\title{
Myocardial Infarction Biomarker Discovery with Integrated Gene Expression, Pathways and Biological Networks analysis
}

\section{Babajan Banaganapalli \\ King Abdulaziz University \\ Noor A. Shaik \\ King Abdulaziz University \\ Ramu Elango \\ King Abdulaziz University \\ Jumana Y. Al-Aama \\ King Abdulaziz University}

Abdulrahman MUJALLI ( $\square$ emajli@kau.edu.sa )

King Abdulaziz University https://orcid.org/0000-0002-8630-3963

\section{Research article}

Keywords: bioinformatics, GEO, myocardial infarction, differentially expressed genes, immune response, inflammation response, biomarkers

Posted Date: June 15th, 2020

DOl: https://doi.org/10.21203/rs.3.rs-34923/v1

License: (9) (1) This work is licensed under a Creative Commons Attribution 4.0 International License.

Read Full License

Version of Record: A version of this preprint was published at Genomics on November 1st, 2020. See the published version at https://doi.org/10.1016/j.ygeno.2020.09.004. 


\section{Abstract \\ Background}

Myocardial infarction (MI) is the most prevalent coronary atherosclerotic heart disease caused by the complex molecular interactions between multiple genes and environment. Molecular exploration of gene expression changes in MI patients is very crucial not just to understand the molecular basis of disease development but also to identify potential therapeutic targets. Therefore, we aim to identify potential biomarkers for the disease development mechanisms and for prognosis of MI using extensive integrated biological network analysis.

\section{Methodology}

Gene expression datasets (GSE66360) generated from 51 healthy controls and 49 endothelial cell samples from patients experiencing acute MI were used to analyze the differentially expressed genes (DEG), protein-protein interactions (PPI), gene network-clusters to annotate the candidate pathways relevant to MI pathogenesis.

\section{Results}

Bioinformatic analysis revealed 810 DEGs, between control and MI samples, with 574 up- and 236 downregulated genes. Their functional annotations with Gene Ontology (GO) has captured several MI targeting biological processes like immune response, inflammation and platelets degranulation. Most significantly DEGs enriched KEGG pathways are related to the following functions: Cytokine-cytokine receptor interaction, TNF and NFkB signaling. By constructing the PPI network using STRING and CytoHubba, seventeen hub and bottleneck genes were found, whose involvement in MI was further confirmed by DisGeNET data. Search in the Open Target Platform reveal unique bottleneck genes as potential target for MI.

\section{Conclusion}

Our integrative bioinformatics analysis of large-scale gene expression data has identified several potential genetic biomarkers associated with early stage MI providing a new insight into molecular mechanism underlying the disease.

\section{Introduction}

Despite the improvement in its management, Myocardial infarction (MI) remains one of the most prevalent and challenging heart diseases due to high morbidity and mortality. The estimated worldwide incidence of MI rises to approximately by 7.29 million people every year [1]. In recent years, experimental 
and epidemiological studies have shown that the vascular inflammation is a central hallmark of cardiac disease by increasing the endothelial damage resulting in the hemodynamic changes and blood thrombogenicity [2-4]. Endothelial cells dysfunction response is observed after $\mathrm{Ml}$ and followed by dysregulated immune system and inflammatory responses [5]. However, mechanisms underlying the changes that occur in immune cells and other signaling pathways during MI remain poorly elucidated. Identification of dysregulated individual genes and signaling pathways is crucial for understanding the pathogenic molecular changes in $\mathrm{Ml}$ and for developing effective treatments with novel targets. Gene expression microarray studies are commonly used for high throughput biomarker identification. Compared to tissue microarray studies, peripheral blood is an attractive tissue for new biomarker screening due to the simplicity and low invasiveness of sample collection. In the present study, we applied integrated analysis of microarray data collected from Ml patients and healthy control to identify and classify differentially expressed genes (DEGs) and to explore the reliable and unique Ml-associated molecular signature profile and their key pathways and screened for potential MI target genes based on genetic association studies. Using systems biology approach, we searched for degree of network interactions and highly connected gene network modules to identify potential biomarkers in Ml.

\section{Results}

\section{Identification of DEGs}

Based on the cutoff criteria (adjusted $\mathrm{P}<0.05$ and $|\log \mathrm{FC}|>1.5$ ), over 20,000 genes were analyzed, and 806 genes were differentially expressed of which 571 genes were up-regulated and 235 down-regulated. After removing the un-mapped DEGs, there were 492 up-regulated and 184 down-regulated DEGs taken up for downstream analysis. Top 10 up- and down-regulated DEGs according to their significance are shown in Table 1 and Table 2. A box plots of the data distribution before and after dataset normalization shown that all chip data reached comparable levels and a volcano plots demonstrates an overview of high expressed genes using $\log \mathrm{FC}$, where the threshold in the volcano plot was $|\log \mathrm{FC}|>1.5$. Subsequently, the heatmap of DEGs was created showing the expression profiles of $\mathrm{MI}$ and non-MI resulted in hierarchical clusters (Fig. 2a-c). 
Table 1

Top 10 significant up- regulated DEGs in Myocardial infarction

\begin{tabular}{|llll|}
\hline Gene ID & Description & P.Value & adj.P.Value \\
\hline NR4A2 & Nuclear Receptor Subfamily 4 Group A Member 2 & $1.43 \mathrm{E}-20$ & $7.83 \mathrm{E}-16$ \\
\hline MAFB & MAF BZIP Transcription Factor B & $8.89 \mathrm{E}-15$ & $4.55 \mathrm{E}-11$ \\
\hline S100A12 & S100 Calcium Binding Protein A12 & $4.15 \mathrm{E}-14$ & $1.26 \mathrm{E}-10$ \\
\hline SLC11A1 & Solute carrier family 11 member 1 & $5.14 \mathrm{E}-14$ & $1.48 \mathrm{E}-10$ \\
\hline LILRB2 & Leukocyte immunoglobulin like receptor B2 & $2.72 \mathrm{E}-13$ & $6.20 \mathrm{E}-10$ \\
\hline IL1B & Interleukin 1 Beta & $5.89 \mathrm{E}-13$ & $1.11 \mathrm{E}-09$ \\
\hline VCAN & Versican & $7.24 \mathrm{E}-13$ & $1.32 \mathrm{E}-09$ \\
\hline ITLN1 & Intelectin 1 & $1.15 \mathrm{E}-12$ & $1.78 \mathrm{E}-09$ \\
\hline CXCL2 & C-X-C Motif Chemokine Ligand 2 & $1.41 \mathrm{E}-12$ & $2.01 \mathrm{E}-09$ \\
\hline CLEC7A & C-Type Lectin Domain Containing 7A & $2.05 \mathrm{E}-10$ & $9.83 \mathrm{E}-08$ \\
\hline
\end{tabular}

Table 2

Top 10 significant down- regulated DEGs in Myocardial infarction

\begin{tabular}{|llll|}
\hline Gene ID & Description & P.Value & adj.P.Value \\
\hline CCR2 & C-C motif chemokine receptor 2 & $1.21 \mathrm{E}-09$ & $4.15 \mathrm{E}-07$ \\
\hline ANKEF1 & Ankyrin repeat and EF-hand domain containing 1 & $3.62 \mathrm{E}-09$ & $1.03 \mathrm{E}-06$ \\
\hline CISH & Cytokine inducible SH2 containing protein & $1.87 \mathrm{E}-08$ & $4.05 \mathrm{E}-06$ \\
\hline ARL10 & ADP ribosylation factor like GTPase 10 & $1.57 \mathrm{E}-07$ & $2.26 \mathrm{E}-05$ \\
\hline XIST & X Inactive Specific Transcript & $1.63 \mathrm{E}-07$ & $2.33 \mathrm{E}-05$ \\
\hline LPAR5 & Iysophosphatidic acid receptor 5 & $4.15 \mathrm{E}-07$ & $4.90 \mathrm{E}-05$ \\
\hline DAB1 & DAB adaptor protein 1 & $4.41 \mathrm{E}-07$ & $5.19 \mathrm{E}-05$ \\
\hline B3GALT2 & Beta-1,3-galactosyltransferase 2 & $6.95 \mathrm{E}-07$ & $7.58 \mathrm{E}-05$ \\
\hline GIMAP4 & GTPase, IMAP family member 4 & $1.11 \mathrm{E}-06$ & 0.00011 \\
\hline KMT5B & Lysine methyltransferase 5B & $6.49 \mathrm{E}-06$ & 0.000451 \\
\hline
\end{tabular}

\section{DEGs GO enrichment analysis}

To characterize the biological role of identified DEGs, functional gene functional annotation and enrichment analysis was performed using DAVID, GO (molecular function, biological process and cellular component), KEGG and Reactome pathways. We combined up and down-regulated DEGs to have a larger 
scale perspective of the biological function. Top GO analysis results are presented in Fig. 3a,b. In biological process category, the most common processes include immune system, regulated exocytosis, response to stimulus and cytokine receptor binding. Under molecular function categories, DEGs were associated with receptor ligand activity, chemokine receptor binding and $\mathrm{G}$ protein coupled receptor (GPCR) binding (Fig. 3a,b).

\section{KEGG and Reactome pathway}

KEGG pathway analysis revealed that the DEGs were significantly enriched in Osteoclast differentiation, TNF signaling, Cytokine-cytokine receptor interaction and NF-kappa B signaling pathways. The results of the Reactome pathways analysis demonstrates an enrichment in neutrophil degranulation, signaling by interleukins and TLR signaling as shown in Fig. 4a,b.

\section{PPI Network and modular analysis}

To explore the interaction of DEGs in MI, DEGs were submitted to STRING database for PPI network construction and Cytoscape software 3.7.2 was used to analyze the network [9]. PPI network of up- and down- regulated DEGs contain 681 nodes and 4704 edges with a mean node degree of 13.8 (Fig. 5). DEGs in the PPI network were ranked by the topological analysis method of degree centrality score of the network where TNF, TLR4, CXCL8, TLR2, STAT3, TLR8, IL1B, VEGFA, MMP9, and JUN had the highest degree of connectivity among DEGs. which may play a critical role in cardiovascular disease. Further analysis of PPI was carried out by MCODE, a Cytoscape plugin used to identify the most significant connected and tightly clustered subnetworks with degree cutoff 2 , node score cutoff $0.2, \mathrm{~K}$-score 2 , and maximum depth of 100. Four modules were extracted from the initially constructed PPI network (Fig. 6ac). Pathway enrichment analysis was then carried out in ClueGO to show pathway specificity for each module (Additional file 1: Fig. S1a-d).

\section{Hub and bottleneck genes}

To investigate the signal of identified modules, we construct PPI network for identified MCODE modules (PPI-MCODE). Maximal Clique Centrality (MCC) method in Cytohubba was used to identify hub genes, centralities and shortest paths method to identify bottlenecks genes. From identified modules, we extracted top 20 hub and 20 bottleneck genes (Fig. 7a,b). The analysis reveals unique twelve genes each as hub and bottleneck genes and eight were classified as hubs as well as bottlenecks. Filtered genes include unique hub genes CCL20, IL1A, CXCL8, CCR2, IL1RN, CXCL2, ICAM1, ITGAX, MMP9, TLR8, CCL3, PTGS2; unique bottleneck genes CDKN1A, LILRB2, FCGR2A, PTX3, MNDA, ATG7, JUN, CD33, DDX58, FCGR1A, FPR1, UBR4; and overlapped hub-bottleneck genes TNF, VEGFA, STAT3, CXCL1, CCL4, TLR2, IL1B, TLR4 where TNF and TLR4 were the most connected gene in the whole PPI network (Table 3). Functional GO, KEGG and Reactome pathways analysis of identified hub and bottleneck genes are illustrated in Additional file 2: Table S1, S2, S3 and S4. 
Table 3

Top 20 significant hubs, bottlenecks and overlapped genes

\begin{tabular}{|lll|}
\hline Category & Up-regulated & $\begin{array}{l}\text { Down- } \\
\text { regulated }\end{array}$ \\
\hline Hubs & $\begin{array}{l}\text { IL1A, CXCL8, ICAM1, TLR8, CXCL2, ITGAX, PTGS2, CCL3, MMP9, } \\
\text { CCL20, IL1RN }\end{array}$ & CCR2 \\
\hline Bottlenecks & $\begin{array}{l}\text { CDKN1A, LILRB2, FCGR2A, PTX3, MNDA, ATG7, JUN, CD33, FCGR1A, } \\
\text { FPR1, UBR4 }\end{array}$ & DDX58 \\
\hline $\begin{array}{l}\text { Hub- } \\
\text { bottleneck }\end{array}$ & $\begin{array}{l}\text { VEGFA, TNF, IL1B, CXCL1, TLR4, TLR2, } \\
\text { CCL4, STAT3 }\end{array}$ & \\
\hline Significant key genes in the network and candidate genes \\
screening
\end{tabular}

In order to identify key genes, we referred to DisGeNET, a comprehensive discovery platform database containing known human gene-disease association to validate our workflow. A total of $32 \mathrm{hub}$ and bottleneck genes, identified by Cytohubba, were mapped into DisGenNET database and MI and HF related genes were extracted. A total of seventeen genes were found to be associated with MI and HF (Fig. 8a). Remaining fifteen genes were resubmitted to DisGeNET for an overview of cardiovascular or other associated diseases. Some of these genes, CCL4, CCL3, CXCL1, JUN, DDX58, FCGR1A and FCGR2A were involved in multiple cardiovascular disease for instance myocardial ischemia, heart valve disease and thrombosis (Fig. 8b). A glimpse of the remaining gene-associated disease is illustrated in Fig. 8c and Table 4. In parallel, we used Open Target platform to screen for distinct biomarkers that correlate with MI (Fig. 9). We first submitted hub and bottleneck genes to Open Target platform and a total of 12 drug target were extracted including PTGS2, VEGFA, TNF, CD33, IL1B, IL1A, MMP9, CCR2, TLR4, ICAM1, CXCL8 and FCGR1A (Additional file 2: Table S5). Separately. We extracted specific MI drug targets list based on genetic association score < 0.2 (Additional file 2: Table S6). A total of $77 \mathrm{MI}$-drug target were then compared with hub and bottleneck genes based on enzyme-substrate, PPI and pathways interaction. Associated genes with MI drug targets were found to be IL1B, IL1A, IL1RN, STAT3, PTX3, PTGS2 and JUN (Additional file 1: Fig. S2). Reanalysis of these genes in DisGeNET database show that all genes were associated with MI except for CD33, FCGR1A and JUN which are bottleneck genes according to our analysis. Available drug for CD33 and FCGR1A and their targets are displayed in Additional file 2: Table S7. Various of identified targets in our workflow have been already in use to improve the clinical outcome in MI patient, such as IL1A, IL1B and PTGS2 as discussed below. We speculated that these genes may play an important role in $\mathrm{MI}$ development and could be potential therapeutic targets for MI treatment. 
Table 4

Associated and unassociated Ml genes

\begin{tabular}{|llll|}
\hline Category & Ml associated gene set & $\begin{array}{l}\text { Cardiovascular disease } \\
\text { associated gene set }\end{array}$ & $\begin{array}{l}\text { Unassociated gene } \\
\text { set }\end{array}$ \\
\hline Hubs & $\begin{array}{l}\text { IL1A, CXCL8, ICAM1, CXCL2, } \\
\text { PTGS2, CCR2, MMP9, IL1RN }\end{array}$ & CCL3 & $\begin{array}{l}\text { TLR8, ITGAX, } \\
\text { CCL20 }\end{array}$ \\
\hline Bottlenecks & CDKN1A, PTX3, ATG7 & $\begin{array}{l}\text { FCGR2A, FCGR1A, JUN, } \\
\text { DDX58 }\end{array}$ & $\begin{array}{l}\text { LILRB2, MNDA, } \\
\text { CD33, FPR1, UBR4 }\end{array}$ \\
$\begin{array}{l}\text { Hub- } \\
\text { bottleneck }\end{array}$ & $\begin{array}{l}\text { VEGFA, TNF, IL1B, TLR4, TLR2, } \\
\text { STAT3 }\end{array}$ & CXCL1, CCL4 & \\
\hline
\end{tabular}

\section{Discussion}

Myocardial infarction is a complex disease where the genetic makeup may contribute to distinct cellular processes and to the development of disease phenotypes $[10,11]$. Ml is associated with systemic inflammatory dysregulated response including elevated levels of circulating inflammatory mediators, and activation of peripheral leukocytes and platelets.

In concordance with previous studies, our work highlights a possible immune change in MI pathology. The crucial role of immune system in myocardial infarction is well established [12,13]. Previous studies suggested an intense immune and inflammatory responses trigger several distinct cardiac pathological conditions including early onset MI [14-16]. The immune signals may indirectly contribute to the reverse remodeling in dilated cardiomyopathy, dilative remodeling, infarcted size increase and heart failure [17, 18].

We found that the highest ranked genes identified in the whole PPI network, beside their role in the immune, inflammatory responses and interleukins signaling pathways, were strongly associated with $\mathrm{MI}$ development including CYBB [19, 20], CXCL2 [21, 22], NRG1[23, 24], VWF [25] and MMP9 [26]. Moreover, TLR family genes (TLR2, TLR4 and TLR10) were also correlated with immune and inflammatory response functions, which suggests their association with $\mathrm{Ml}$ development $[27,28]$.

Identification of key genes in major pathways might be an attractive therapeutic target for MI. MCODE analysis found four tightly connected sub-networks (modules) containing most of the topologically significant nodes of the whole networks. The transcriptional profiling presented in identified modules demonstrating the relationship variability in the functional biological pathways of MI. Several identified hub genes were significantly associated with MI. Thrombomodulin (THBD) is an endothelial anticoagulant protein, involved in anti-inflammatory responses, including innate immunity, fibrinolysis and complement activity $[29,30]$. Genetic studies linked several polymorphisms within THBD to be associated with higher risk of coronary artery disease and myocardial infarction [31-35].

Another identified gene is Superoxide Dismutase 2 (SOD2). SOD2 is one of the major mitochondrial antioxidant enzymes. Homozygous mice for SOD2 have a severe phenotype, heart and liver 
complications, metabolic acidosis, and early neonatal death [36]. Recent study showed that plasmatic concentration of SOD2 was higher in CAD than in healthy control [37, 38]. Dubois-Deruy et al. showed a direct interaction between circulatory MicroRNAs and SOD2 in heart failure post MI rat model [39]. These data indicate that SOD2 might serve as a potential biomarker candidate for post-myocardial infarction.

Endothelin 1 (EDN1) is a potent endogenous vasoconstrictor and a crucial modulator of neutrophil function $[40,41]$. High plasmatic levels of EDN1 have been linked to poor clinical outcomes after STsegment elevation myocardial infarction (STEMI), microvascular obstruction presence and were found to be a strong predictor of 1-year survival post-MI [42-44].

TLR2 a member of TLR family was also identified as DEGs in MI and an important node in MCODE modules. TLR2 is a key player in innate immunity, inflammatory response and pathogenesis of heart failure after MI [45]. TLR2 modulates ventricular remodeling after myocardial infarction and its expression is negatively correlated with the inflammatory response which may influence myocardial ischemia-reperfusion injury therapy. Monoclonal anti-TLR2 antibody causes a pronounced reduction of leukocyte influx, cytokine production and preserves cardiac function and geometry in vivo [46]. TLR2 deficiency has also been shown to have a protective effect in a mouse $[47,48]$. These experimental evidences increase the potential of TLR2 as a therapeutic target.

Hubs and bottlenecks are crucial components in signaling networks as they are hypothesized to be encoded by essential genes and more relevant to biologically significant process with respect to the disease [49-51]. We filtered out 32 key genes by using Cytohubba. We utilized the gene expression data to infer the disease related gene expression to identify candidate regulatory genes and to infer signaling pathway networks directly from candidate genes expression. According to DisGeNET database, role of 17 hub and bottleneck genes in $\mathrm{Ml}$ is supported by many experimental work across the globe $[52-55,55-63]$ including VEGFA, which limits myocardial damage in MI animal models [63], ICAM1, implicated in pathophysiologic responses and neutrophil infiltration [55,61], TLR4 that mediates maladaptive left ventricular remodeling and impairs cardiac function [62]. Interleukins family members such as IL1A and IL1B as well as PTGS2 which will be discussed further below.

Detection of these key MI related genes indicated that our framework of integrated bioinformatics analysis pipeline is sensitive enough to rapidly identify potential target gene biomarkers or novel drug targets for any complex disease. Remaining genes in hubs and bottlenecks network were tightly connected with known Ml functions. Prior to the present study, few studies have addressed the gaps in identifying potential biomarkers in Ml early stage[64-66]. Our strategy in identifying distinct biomarkers that correlate with $\mathrm{Ml}$ and its development were based on comparing predicted physical interaction and genetic association of Ml-gene targets using Open Target Platform. Twelve genes from the hubs and bottlenecks were target for other diseases (Additional file 2: Table S5) and seven hubs and one bottleneck gene in total were linked to MI (Additional file 1: Fig. S2). Among identified targets IL1A and IL1B, member of the interleukin-1 gene family, which are proinflammatory factors produced by different cell types, including endothelial cells, in response to various stimuli [67-69]. The intense inflammatory response is a 
key process is which play a central role in many cardiovascular diseases including Myocardial infarction [70-72]. Targeting inflammatory pathways key genes such as Interleukin-1 members in cardiovascular disease in order to neutralization elimination of specific activated inflammatory mediators may contribute to protective effect in the infarcted heart without disturbing the reparative response [73]. Variants in IL1A and IL1B are associated with acute MI as well as heart failure [74-76], Interleukin-1 blockers are used to improve clinical outcome in patients with prior MI. There are currently four clinically available IL-1 blockers, anakinra, rilonacept, canakinumab and gevokizumab each with a different efficacy and safety profile [77]. For instance, IL-1 blocker, was originally approved for the treatment of rheumatoid arthritis (anakinra) [78]. However, It has also been successfully studied in small clinical trials to test its effectiveness in patients with myocardial infarction and favorably affect cardiac remodeling and exhibit a protective effect from post-infarction heart failure development [79-81]. Nowadays, only canakinumab has an indication for cardiovascular disease [82].

Our study revealed that PTGS2 is one of the key players in MI development. PTGS2, also known as COX2 , is inducible enzyme that plays an important role in several pathophysiological processes, including inflammation, angiogenesis, and tumorigenesis $[83,84]$. GO analysis showed that PTGS2 was enriched in TNF and Interleukins signaling pathways. PTGS2 has previously been associated with $\mathrm{Ml}$, ischemic heart disease and stroke risk $[56,85,86]$. However, the role of selective COX-2 inhibitors in medical practice remain controversial. Saito el al., have shown that COX-2 induction during MI appears to contribute to myocardial injury, and treatment with the specific inhibitor of the enzyme ameliorated the course of the disease [87]. Similarly, COX-2 inhibition was shown to be associated with improved hemodynamics and lower cardiomyocyte apoptotic rates in a genetically modified mouse model of non-ischaemic heart failure and in a canine model of myocardial ischemia-reperfusion $[88,89]$. Others have shown that COX-2 inhibitors may be detrimental for myocardial infarction [90, 91].

\section{Conclusion}

By using a series of bioinformatics analysis based on DEGs between MI patient and healthy sample, we illustrated the hub, bottleneck genes and pathways as markers of inflammatory response which may be involved in the early stage of MI. In parallel, we have generated a candidate Ml genes list by using DisGeNET and Open Target platform. Identification of MI specific genes and pathways, which predispose individuals to $\mathrm{Ml}$, will facilitate the targeting of novel therapeutics and treatment strategies in development. These results may provide insight for the study of $\mathrm{Ml}$ therapeutic targets. However, a limitation of the present study was that the identified candidate genes in MI were not experimentally validated, which may become a focus of future studies.

\section{Methods}

\section{Public Microarray domain Data collection}


MI dataset was obtained from NCBI Gene Expression Omnibus (GEO)

(http://www.ncbi.nlm.nih.gov/geo/), a functional genomics public database for data repository of high throughput gene expression. GSE66360 [GPL570, (HG-U133_Plus_2), Affymetrix Human Genome U133 Plus 2.0 Array] dataset consists of microarray data from isolated circulating endothelial cells from patients experiencing acute myocardial infarction $(n=49)$ and healthy subject $(n=50)$. The healthy samples had no previous history of cardiovascular diseases or other comorbidities. No ethics committee approval or patient consent were required for the present study.

\section{Study design and global data preprocessing and differentially expressed genes screening}

The study design was performed according to the experimental workflow in Fig. 1. By using robust multiarray average algorithm in R package software version 3.6.3; (http://www.R-project.org/), datasets were analyzed with the Affymetrix platform to convert raw array data into expression value, followed by background correction, quintile normalization and probe summarization. Differentially Expressed Genes (DEGs) from chosen dataset GSE66360 was identified between the MI and non-MI groups using affy package in R, a Volcano plot was generated to assess the overall DEGs. The limma package was then used to select DEGs and paired t-test to analyze the statistical significance of the observed DEG patterns. Benjamini-Hochberg correction method was used for p-value adjustment to false discovery rate (FDR). FDR $<0.05$, and $|\log F C|>1.5$ was set as a cutoff point for DEGs selection. Finally, the DEGs were divided into up- and down- regulated genes.

\section{DEGs functions in MI, gene ontology and signaling pathway enrichment analysis}

Multiple online databases like (DAVID, Panther (http://www.pantherdb.org/) and GO (http://geneontology.org/)) were used to annotate and analyze the functional enrichment of DEGs according to their molecular function, the biological process and cellular component. Pathway enrichment analysis was conducted using Kyoto Encyclopedia of Genes and Genomes (KEGG) pathways (http://www.genome.jp/kegg) and Reactome (http://www.reactome.org) databases. The cutoff point of significance was $p<0.05$. Visual functional presentation for genes and gene clusters were carried out using the R package clusterProfiler [6].

\section{PPI network construction and module analysis}

Network construction for Protein-Protein Interaction (PPI) was performed by the Retrieval of Interacting Genes from STRING Database (http://www.string-db.org/). Cytoscape software

(http://www.cytoscape.org/) was used for PPI network visualization. Modular and cluster analysis of the PPI network were performed in MCODE, a Cytoscape plugin, to identify functional gene communities in the subnetwork with degree cutoff 2, node score cutoff 0.2, K-score 2, and maximum depth of 100. Enrichment analysis and pathway annotation of functional genes in the MCODE identified sub-network were searched using functional annotation tool in Cytoscape ClueGO. PPI-MCODE modules was then 
combined and divide into two groups hub and bottleneck genes top genes were ranked computationally using the Cytoscape plugin Cytohubba based on their connectivity within the PPI-MCODE network [7].

\section{DEGs candidate selection}

To prioritize and identify disease candidate genes, we used the external databases: DisGeNET database (http://www.disgenet.org) which is a discovery platform of collection of known genes and variantshuman disease associations from various expert databases and the literature [8]. We searched MI-related genes, as well as Heart Failure (HF) using DisGeNET. We then used Open Targets

(https://www.opentargets.org/) a drug discovery platform which also has a disease ontology associated with the human pathophysiology, to predict de novo potential therapeutic targets based on associated drug targets with hub and bottleneck genes and available MI targets.

\section{Declarations}

\section{Acknowledgements}

This work was supported by The Research and Development Office (RDO) of the Ministry of Education, Post-Doctoral Fellowships program, Kingdom of Saudi Arabia, (grant no. 465).

\section{Disclosure statement}

The authors declare that they have no competing interests.

\section{Contributions}

$\mathrm{AM}$ and $\mathrm{BB}$ designed the framework, performed the bioinformatics and data analysis, and drafted the manuscript. NS participated in design and wrote part of the manuscript. RE made contributions to conception and design and interpretation of data. RE and JA provided funding and supervision for the work. AM, BB, NS, RE and JA contributed to writing the paper. All authors read and approved the final manuscript

\section{References}

1. Roth GA, Johnson C, Abajobir A, Abd-Allah F, Abera SF, Abyu G, et al. Global, Regional, and National Burden of Cardiovascular Diseases for 10 Causes, 1990 to 2015. J Am Coll Cardiol. 2017;70:1-25.

2. Ferrucci L, Fabbri E. Inflammageing: chronic inflammation in ageing, cardiovascular disease, and frailty. Nat Rev Cardiol. 2018;15:505-22.

3. Matsuzawa Y, Lerman A. Endothelial Dysfunction and Coronary Artery Disease: Assessment, Prognosis and Treatment. Coron Artery Dis. 2014;25:713-24.

4. Cecchi E, Giglioli C, Valente S, Lazzeri C, Gensini GF, Abbate R, et al. Role of hemodynamic shear stress in cardiovascular disease. Atherosclerosis. 2011;214:249-56. 
5. Widmer RJ, Lerman A. Endothelial dysfunction and cardiovascular disease. Glob Cardiol Sci Pract. 2014;2014:291-308.

6. Yu G, Wang L-G, Han Y, He Q-Y. clusterProfiler: an R package for comparing biological themes among gene clusters. Omics J Integr Biol. 2012;16:284-7.

7. Chin $\mathrm{C}-\mathrm{H}$, Chen $\mathrm{S}-\mathrm{H}, \mathrm{Wu} \mathrm{H}-\mathrm{H}, \mathrm{Ho} \mathrm{C}-\mathrm{W}, \mathrm{Ko} \mathrm{M}-\mathrm{T}$, Lin C-Y. cytoHubba: identifying hub objects and subnetworks from complex interactome. BMC Syst Biol. 2014;8(Suppl 4):11.

8. Piñero J, Bravo À, Queralt-Rosinach N, Gutiérrez-Sacristán A, Deu-Pons J, Centeno E, et al. DisGeNET: a comprehensive platform integrating information on human disease-associated genes and variants. Nucleic Acids Res. 2017;45:D833-9.

9. Saito R, Smoot ME, Ono K, Ruscheinski J, Wang P-L, Lotia S, et al. A travel guide to Cytoscape plugins. Nat Methods. 2012;9:1069-76.

10. Dai X, Wiernek S, Evans JP, Runge MS. Genetics of coronary artery disease and myocardial infarction. World J Cardiol. 2016;8:1-23.

11. Yamada Y, Ichihara S, Nishida T. Molecular genetics of myocardial infarction. Genomic Med. 2008;2:7-22.

12. Lai S-L, Marín-Juez R, Stainier DYR. Immune responses in cardiac repair and regeneration: a comparative point of view. Cell Mol Life Sci. 2019;76:1365-80.

13. Gentek R, Hoeffel G. The Innate Immune Response in Myocardial Infarction, Repair, and Regeneration. Adv Exp Med Biol. 2017;1003:251-72.

14. Ruparelia N, Godec J, Lee R, Chai JT, Dall'Armellina E, McAndrew D, et al. Acute myocardial infarction activates distinct inflammation and proliferation pathways in circulating monocytes, prior to recruitment, and identified through conserved transcriptional responses in mice and humans. Eur Heart J. 2015;36:1923-34.

15. Deten A, Volz HC, Briest W, Zimmer H-G. Cardiac cytokine expression is upregulated in the acute phase after myocardial infarction. Experimental studies in rats. Cardiovasc Res. 2002;55:329-40.

16. Frangogiannis NG. The inflammatory response in myocardial injury, repair, and remodelling. Nat Rev Cardiol. 2014;11:255-65.

17. Frangogiannis NG. Pathophysiology of Myocardial Infarction. Compr Physiol. 2015;5:1841-75.

18. Vilahur G, Badimon L. Ischemia/reperfusion activates myocardial innate immune response: the key role of the toll-like receptor. Front Physiol. 2014;5. doi:10.3389/fphys.2014.00496.

19. Krijnen PJ, Meischl C, Hack CE, Meijer CJLM, Visser CA, Roos D, et al. Increased Nox2 expression in human cardiomyocytes after acute myocardial infarction. J Clin Pathol. 2003;56:194-9.

20. Heymes C, Bendall JK, Ratajczak P, Cave AC, Samuel J-L, Hasenfuss G, et al. Increased myocardial NADPH oxidase activity in human heart failure. J Am Coll Cardiol. 2003;41:2164-71.

21. Mylonas KJ, Turner NA, Bageghni SA, Kenyon CJ, White Cl, McGregor K, et al. 11ß-HSD1 suppresses cardiac fibroblast CXCL2, CXCL5 and neutrophil recruitment to the heart post MI. J Endocrinol. 2017;233:315-27. 
22. Guo L-Y, Yang F, Peng L-J, Li Y-B, Wang A-P. CXCL2, a new critical factor and therapeutic target for cardiovascular diseases. Clin Exp Hypertens. 2020;42:428-37.

23. Odiete O, Hill MF, Sawyer DB. Neuregulin in cardiovascular development and disease. Circ Res. 2012;111:1376-85.

24. Mendes-Ferreira P, De Keulenaer GW, Leite-Moreira AF, Brás-Silva C. Therapeutic potential of neuregulin-1 in cardiovascular disease. Drug Discov Today. 2013;18:836-42.

25. Sonneveld MAH, de Maat MPM, Leebeek FWG. Von Willebrand factor and ADAMTS13 in arterial thrombosis: a systematic review and meta-analysis. Blood Rev. 2014;28:167-78.

26. DeLeon-Pennell KY, Meschiari CA, Jung M, Lindsey ML. Matrix Metalloproteinases in Myocardial Infarction and Heart Failure. Prog Mol Biol TransI Sci. 2017;147:75-100.

27. Van Der Pouw Kraan CTM, Bernink FJP, Baggen JM, Beek AM, Diamant M, Chen WJY, et al. Toll like receptor activation during human acute myocardial infarction with ST elevation. Eur Heart J. 2013;34:suppl_1. doi:10.1093/eurheartj/eht309.2838.

28. Yang Y, Lv J, Jiang S, Ma Z, Wang D, Hu W, et al. The emerging role of Toll-like receptor 4 in myocardial inflammation. Cell Death Dis. 2016;7:e2234.

29. Lobato RL, White WD, Mathew JP, Newman MF, Smith PK, McCants CB, et al. Thrombomodulin Gene Variants are Associated with Increased Mortality Following Coronary Artery Bypass Surgery in Replicated Analyses. Circulation. 2011;124(11 Suppl):143-8.

30. Morser J. Thrombomodulin links coagulation to inflammation and immunity. Curr Drug Targets. 2012;13:421-31.

31. Wu KK, Aleksic N, Ahn C, Boerwinkle E, Folsom AR, Juneja H, et al. Thrombomodulin Ala455Val polymorphism and risk of coronary heart disease. Circulation. 2001;103:1386-9.

32. Park H-Y, Nabika T, Jang Y, Kwon HM, Cho SY, Masuda J. Association of G-33A polymorphism in the thrombomodulin gene with myocardial infarction in Koreans. Hypertens Res Off J Jpn Soc Hypertens. 2002;25:389-94.

33. Alkhiary W, Abdalaal M, El-Saddik AM. The relation of thrombomodulin G33A and C1418T gene polymorphisms to the risk of acute myocardial infarction in Egyptians. Egypt J Med Hum Genet. 2018;19:19-22-19-22.

34. Dogra R, Das R, Ahluwalia J, Kumar RM, Talwar KK. Association of thrombomodulin gene polymorphisms and plasma thrombomodulin levels with acute myocardial infarction in north Indian patients. Clin Appl Thromb Off J Int Acad Clin Appl Thromb. 2013;19:637-43.

35. Doggen CJ, Kunz G, Rosendaal FR, Lane DA, Vos HL, Stubbs PJ, et al. A mutation in the thrombomodulin gene, $127 \mathrm{G}$ to $\mathrm{A}$ coding for Ala25Thr, and the risk of myocardial infarction in men. Thromb Haemost. 1998;80:743-8.

36. Melov S, Coskun P, Patel M, Tuinstra R, Cottrell B, Jun AS, et al. Mitochondrial disease in superoxide dismutase 2 mutant mice. Proc Natl Acad Sci U S A. 1999;96:846-51. 
37. Zengin E, Sinning C, Zeller T, Rupprecht H-J, Schnabel RB, Lackner K-J, et al. Activity of superoxide dismutase copper/zinc type and prognosis in a cohort of patients with coronary artery disease. Biomark Med. 2015;9:597-604.

38. $10.1155 / 2016 / 3708905$

Peng J-R, Lu T-T, Chang H-T, Ge X, Huang B, Li W-M. Elevated Levels of Plasma Superoxide Dismutases 1 and 2 in Patients with Coronary Artery Disease. BioMed Res Int. 2016;2016. doi:10.1155/2016/3708905.

39. Dubois-Deruy E, Cuvelliez M, Fiedler J, Charrier H, Mulder P, Hebbar E, et al. MicroRNAs regulating superoxide dismutase 2 are new circulating biomarkers of heart failure. Sci Rep. 2017;7. doi:10.1038/s41598-017-15011-6.

40. Yanagisawa M, Kurihara H, Kimura S, Tomobe Y, Kobayashi M, Mitsui Y, et al. A novel potent vasoconstrictor peptide produced by vascular endothelial cells. Nature. 1988;332:411-5.

41. López Farré A, Riesco A, Espinosa G, Digiuni E, Cernadas MR, Alvarez V, et al. Effect of endothelin-1 on neutrophil adhesion to endothelial cells and perfused heart. Circulation. 1993;88:1166-71.

42. Yip H-K, Wu C-J, Chang H-W, Yang C-H, Yu T-H, Chen Y-H, et al. Prognostic value of circulating levels of endothelin-1 in patients after acute myocardial infarction undergoing primary coronary angioplasty. Chest. 2005;127:1491-7.

43. Freixa X, Heras M, Ortiz JT, Argiró S, Guasch E, Doltra A, et al. Usefulness of endothelin-1 assessment in acute myocardial infarction. Rev Esp Cardiol. 2011;64:105-10.

44. Khan IA. Role of Endothelin-1 in Acute Myocardial Infarction. CHEST. 2005;127:1474-6.

45. Ueland T, Espevik T, Kjekshus J, Gullestad L, Omland T, Squire IB, et al. Mannose binding lectin and soluble Toll-like receptor 2 in heart failure following acute myocardial infarction. J Card Fail. 2006;12:659-63.

46. Arslan F, Smeets MB, O’Neill LAJ, Keogh B, McGuirk P, Timmers L, et al. Myocardial ischemia/reperfusion injury is mediated by leukocytic toll-like receptor-2 and reduced by systemic administration of a novel anti-toll-like receptor-2 antibody. Circulation. 2010;121:80-90.

47. Sakata Y, Dong J-W, Vallejo JG, Huang C-H, Baker JS, Tracey KJ, et al. Toll-like receptor 2 modulates left ventricular function following ischemia-reperfusion injury. Am J Physiol Heart Circ Physiol. 2007;292:H503-9.

48. Favre J, Musette P, Douin-Echinard V, Laude K, Henry J-P, Arnal J-F, et al. Toll-like receptors 2-deficient mice are protected against postischemic coronary endothelial dysfunction. Arterioscler Thromb Vasc Biol. 2007;27:1064-71.

49. Jeong H, Mason SP, Barabási A-L, Oltvai ZN. Lethality and centrality in protein networks. Nature. 2001;411:41-2.

50. Park K, Kim D. Localized network centrality and essentiality in the yeast-protein interaction network. Proteomics. 2009;9:5143-54.

51. Yu H, Kim PM, Sprecher E, Trifonov V, Gerstein M. The Importance of Bottlenecks in Protein Networks: Correlation with Gene Essentiality and Expression Dynamics. PLoS Comput Biol. 2007;3. 
doi:10.1371/journal.pcbi.0030059.

52. Harhous Z, Booz GW, Ovize M, Bidaux G, Kurdi M. An Update on the Multifaceted Roles of STAT3 in the Heart. Front Cardiovasc Med. 2019;6. doi:10.3389/fcrm.2019.00150.

53. Bujak M, Frangogiannis NG. The role of Interleukin-1 in the pathogenesis of heart disease. Arch Immunol Ther Exp (Warsz). 2009;57:165-76.

54. Ong S-B, Hernández-Reséndiz S, Crespo-Avilan GE, Mukhametshina RT, Kwek X-Y, Cabrera-Fuentes $\mathrm{HA}$, et al. Inflammation following acute myocardial infarction: Multiple players, dynamic roles, and novel therapeutic opportunities. Pharmacol Ther. 2018;186:73-87.

55. Benson V, McMahon AC, Lowe HC. ICAM-1 in acute myocardial infarction: a potential therapeutic target. Curr Mol Med. 2007;7:219-27.

56. Xie X, Ma Y, Fu Z, Yang Y, Ma X, Chen B, et al. Association of polymorphisms of PTGS2 and CYP8A1 with myocardial infarction. Clin Chem Lab Med. 2009;47:347-52.

57. Yu L, Feng Z. The Role of Toll-Like Receptor Signaling in the Progression of Heart Failure. Mediators Inflamm. 2018;2018:e9874109. doi:https://doi.org/10.1155/2018/9874109.

58. Zhao T, Zhao W, Chen Y, Ahokas RA, Sun Y. Vascular endothelial growth factor (VEGF)-A: role on cardiac angiogenesis following myocardial infarction. Microvasc Res. 2010;80:188-94.

59. Salio M, Chimenti S, De Angelis N, Molla F, Maina V, Nebuloni M, et al. Cardioprotective function of the long pentraxin PTX3 in acute myocardial infarction. Circulation. 2008;117:1055-64.

60. Rodríguez I, Coto E, Reguero JR, González P, Andrés V, Lozano I, et al. Role of the CDKN1A/p21, $\mathrm{CDKN} 1 \mathrm{C} / \mathrm{p} 57$, and CDKN2A/p16 genes in the risk of atherosclerosis and myocardial infarction. Cell Cycle Georget Tex. 2007;6:620-5.

61. Lin Q-Y, Lang P-P, Zhang Y-L, Yang X-L, Xia Y-L, Bai J, et al. Pharmacological blockage of ICAM-1 improves angiotensin II-induced cardiac remodeling by inhibiting adhesion of LFA-1 + monocytes. Am J Physiol-Heart Circ Physiol. 2019;317:H1301-11.

62. Timmers L, Sluijter JPG, van Keulen JK, Hoefer IE, Nederhoff MGJ, Goumans M-J, et al. Toll-like receptor 4 mediates maladaptive left ventricular remodeling and impairs cardiac function after myocardial infarction. Circ Res. 2008;102:257-64.

63. Carlsson L, Clarke JC, Yen C, Gregoire F, Albery T, Billger M, et al. Biocompatible, Purified VEGF-A mRNA Improves Cardiac Function after Intracardiac Injection 1 Week Post-myocardial Infarction in Swine. Mol Ther Methods Clin Dev. 2018;9:330-46.

64. Parahuleva MS, Euler G, Mardini A, Parviz B, Schieffer B, Schulz R, et al. Identification of microRNAs as potential cellular monocytic biomarkers in the early phase of myocardial infarction: a pilot study. Sci Rep. 2017;7:15974.

65. Wu K, Zhao Q, Li Z, Li N, Xiao Q, Li X, et al. Bioinformatic screening for key miRNAs and genes associated with myocardial infarction. FEBS Open Bio. 2018;8:897-913.

66. Zhang G, Li J, Sun H, Yang G. Screening for the Biomarkers Associated with Myocardial Infarction by Bioinformatics Analysis. J Comput Biol J Comput Mol Cell Biol. 2019. 
67. Bochner BS, Luscinskas FW, Gimbrone MA, Newman W, Sterbinsky SA, Derse-Anthony CP, et al. Adhesion of human basophils, eosinophils, and neutrophils to interleukin 1-activated human vascular endothelial cells: contributions of endothelial cell adhesion molecules. J Exp Med. 1991;173:1553-7.

68. Dinarello CA. Biologic basis for interleukin-1 in disease. Blood. 1996;87:2095-147.

69. Pfeiler S, Winkels H, Kelm M, Gerdes N. IL-1 family cytokines in cardiovascular disease. Cytokine. 2019;122:154215.

70. Aukrust P, Halvorsen B, Yndestad A, Ueland T, Øie E, Otterdal K, et al. Chemokines and cardiovascular risk. Arterioscler Thromb Vasc Biol. 2008;28:1909-19.

71. Hansson GK. Inflammation, atherosclerosis, and coronary artery disease. N Engl J Med. 2005;352:1685-95.

72. Saxena A, Russo I, Frangogiannis NG. Inflammation as a therapeutic target in myocardial infarction: learning from past failures to meet future challenges. Transl Res J Lab Clin Med. 2016;167:152-66.

73. Christia P, Frangogiannis NG. Targeting inflammatory pathways in myocardial infarction. Eur J Clin Invest. 2013;43:986-95.

74. Coverstone ED, Bach RG, Chen L, Bierut LJ, Li AY, Lenzini PA, et al. A novel genetic marker of decreased inflammation and improved survival after acute myocardial infarction. Basic Res Cardiol. 2018;113:38.

75. Henningsen KMA, Olesen MS, Pedersen M, Nielsen L, Hauns $\varnothing$ S, Bruunsgaard $H$, et al. Single nucleotide polymorphisms in inflammatory genes and the risk of early onset of lone atrial fibrillation. Inflamm Res Off J Eur Histamine Res Soc Al. 2010;59:965-9.

76. Chen X, Chen X, Xu Y, Yang W, Wu N, Ye H, et al. Association of six CpG-SNPs in the inflammationrelated genes with coronary heart disease. Hum Genomics. 2016;10 Suppl 2. doi:10.1186/s40246016-0067-1.

77. Buckley LF, Abbate A. Interleukin-1 blockade in cardiovascular diseases: a clinical update. Eur Heart J. 2018;39:2063-9.

78. Furst DE. Anakinra: review of recombinant human interleukin-I receptor antagonist in the treatment of rheumatoid arthritis. Clin Ther. 2004;26:1960-75.

79. Abbate A, Kontos MC, Grizzard JD, Biondi-Zoccai GGL, Van Tassell BW, Robati R, et al. Interleukin-1 Blockade With Anakinra to Prevent Adverse Cardiac Remodeling After Acute Myocardial Infarction (Virginia Commonwealth University Anakinra Remodeling Trial [VCU-ART] Pilot Study). Am J Cardiol. 2013;111:1394-400.

80. Abbate A, Van Tassell BW, Biondi-Zoccai G, Kontos MC, Grizzard JD, Spillman DW, et al. Effects of interleukin-1 blockade with anakinra on adverse cardiac remodeling and heart failure after acute myocardial infarction [from the Virginia Commonwealth University-Anakinra Remodeling Trial (2) (VCU-ART2) pilot study]. Am J Cardiol. 2013;111:1394-400.

81. Abbate A, Kontos MC, Abouzaki NA, Melchior RD, Thomas C, Van Tassell BW, et al. Comparative safety of interleukin-1 blockade with anakinra in patients with ST-segment elevation acute 
myocardial infarction (from the VCU-ART and VCU-ART2 pilot studies). Am J Cardiol. 2015;115:28892.

82. Ridker PM, Everett BM, Thuren T, MacFadyen JG, Chang WH, Ballantyne C, et al. Antiinflammatory Therapy with Canakinumab for Atherosclerotic Disease. N Engl J Med. 2017;377:1119-31.

83. Kuwano T, Nakao S, Yamamoto H, Tsuneyoshi M, Yamamoto T, Kuwano M, et al. Cyclooxygenase 2 is a key enzyme for inflammatory cytokine-induced angiogenesis. FASEB J Off Publ Fed Am Soc Exp Biol. 2004;18:300-10.

84. Liu B, Qu L, Yan S. Cyclooxygenase-2 promotes tumor growth and suppresses tumor immunity. Cancer Cell Int. 2015;15:106.

85. Cipollone F, Toniato E, Martinotti S, Fazia M, lezzi A, Cuccurullo C, et al. A Polymorphism in the Cyclooxygenase 2 Gene as an Inherited Protective Factor Against Myocardial Infarction and Stroke. JAMA. 2004;291:2221-8.

86. Ross S, Eikelboom J, Anand SS, Eriksson N, Gerstein HC, Mehta S, et al. Association of cyclooxygenase-2 genetic variant with cardiovascular disease. Eur Heart J. 2014;35:2242-8.

87. Saito T, Rodger IW, Shennib H, Hu F, Tayara L, Giaid A. Cyclooxygenase-2 (COX-2) in acute myocardial infarction: cellular expression and use of selective COX-2 inhibitor. Can J Physiol Pharmacol. 2003;81:114-9.

88. Zhang Z, Vezza R, Plappert T, McNamara P, Lawson JA, Austin S, et al. COX-2-dependent cardiac failure in Gh/tTG transgenic mice. Circ Res. 2003;92:1153-61.

89. Carnieto A, Dourado PMM, da Luz PL, Chagas ACP. Selective Cyclooxygenase-2 Inhibition Protects Against Myocardial Damage in Experimental Acute Ischemia. Clin Sao Paulo Braz. 2009;64:245-52.

90. Hippisley-Cox J, Coupland C. Risk of myocardial infarction in patients taking cyclo-oxygenase-2 inhibitors or conventional non-steroidal anti-inflammatory drugs: population based nested casecontrol analysis. BMJ. 2005;330:1366.

91. Brophy JM, Lévesque LE, Zhang B. The coronary risk of cyclo-oxygenase-2 inhibitors in patients with a previous myocardial infarction. Heart Br Card Soc. 2007;93:189-94.

\section{Figures}




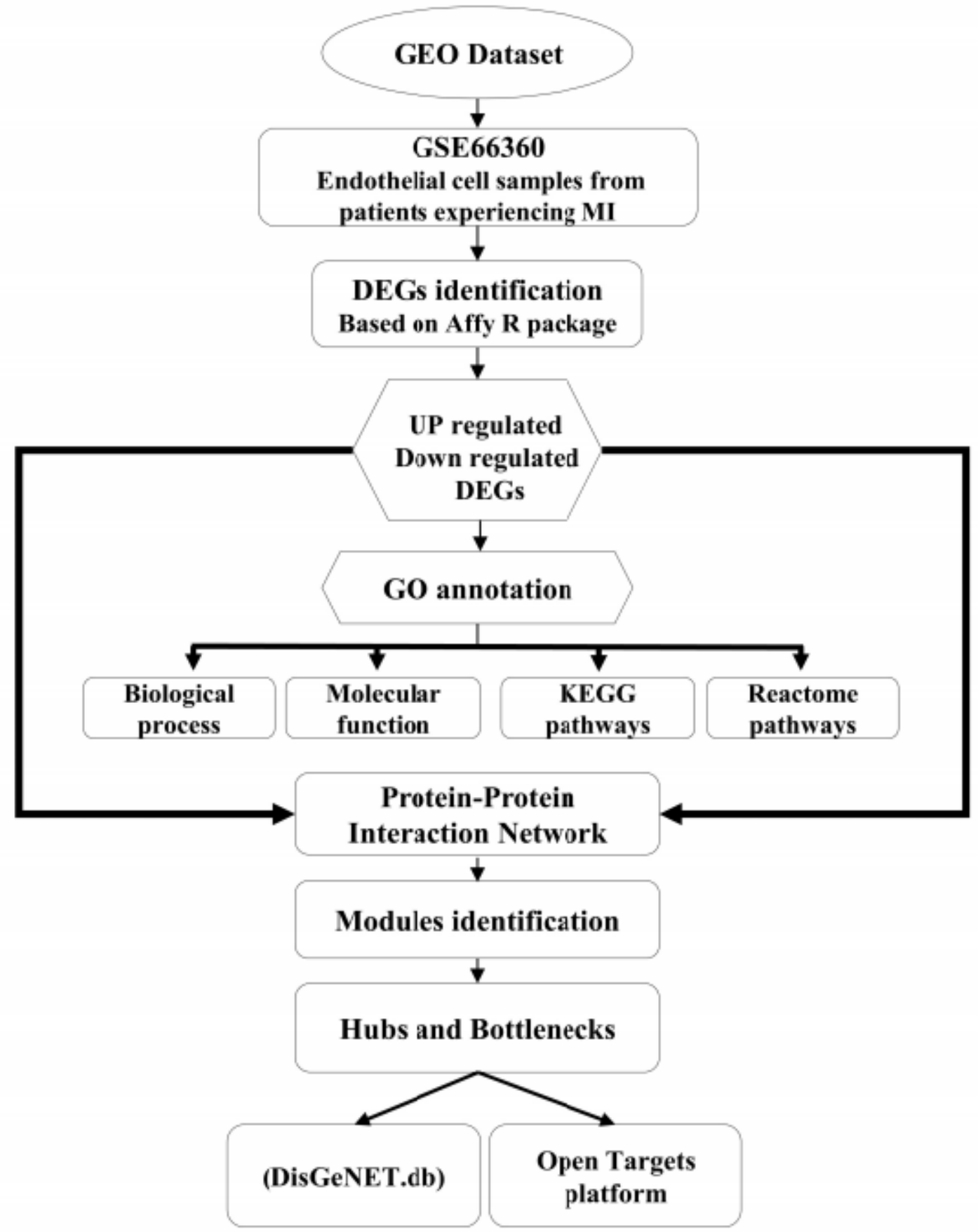

Figure 1

Workflow of GEO dataset preprocessing, DEGs screening and GO enrichment analysis. DEGs, differentially expressed genes, GEO, Gene Expression Omnibus, PPI, protein-protein interaction and Go, gene ontology. 


\section{A}

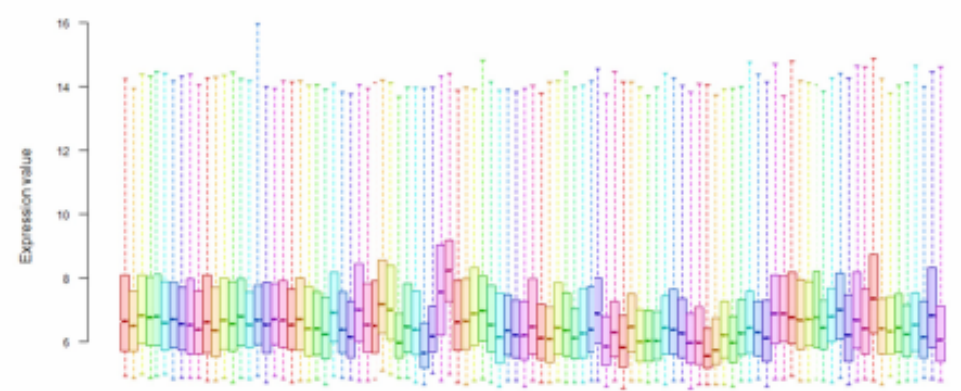

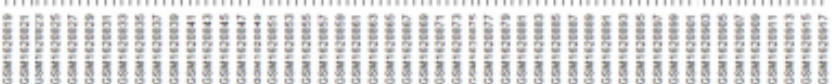

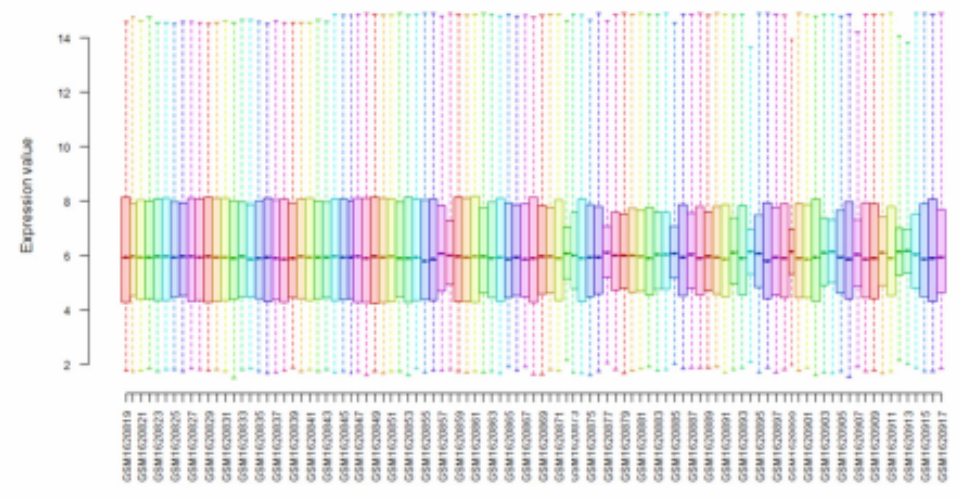

B

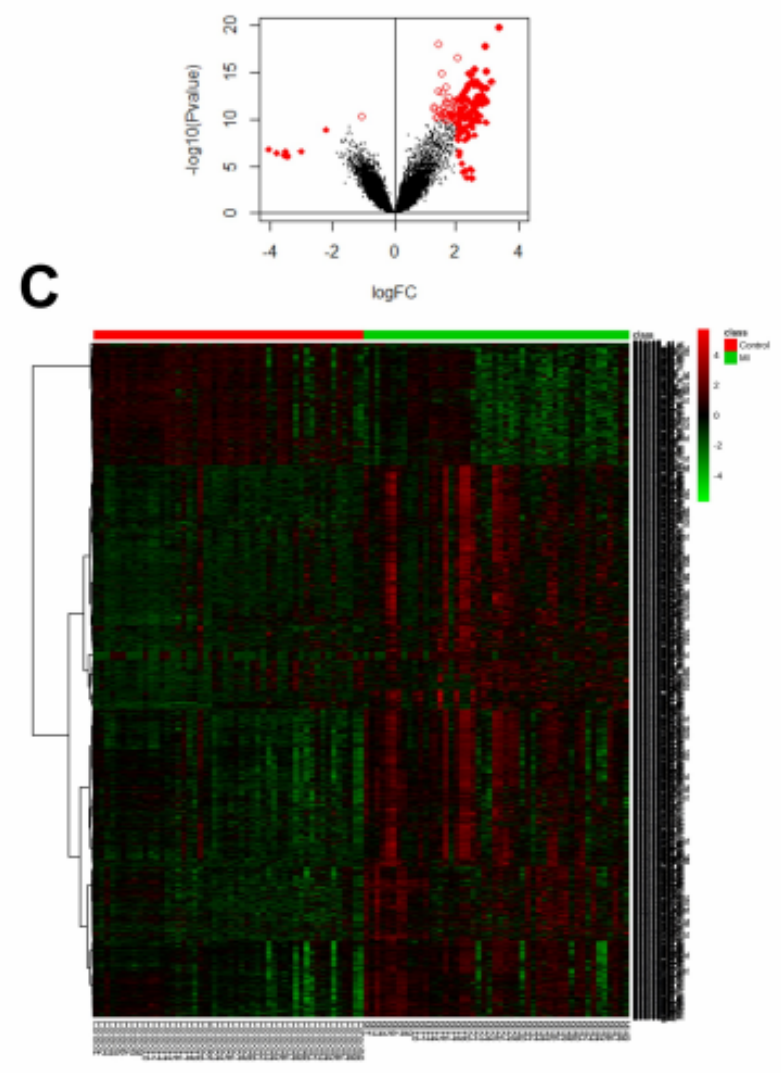

\section{Figure 2}

Identification of DEGs in each GEO data set. (a) Boxplots show the expression intensity of each sample for GSE66360 before (upper panel) and after (lower panel) normalization. (b) Volcano plot in microarray representing top DEGs in GSE66360 between MI patient and healthy control, are represented in red dots satisfying the criteria of $\log F C$ value $>+4$ or $<-4$ and $P<0.05$. Positive red dots indicate up-regulated genes and negative red dots indicates down-regulated genes. (c) The expression heatmap depicting expression levels of significantly different upregulated and downregulated genes. The color indicates high expression (red) and low expression (green). 

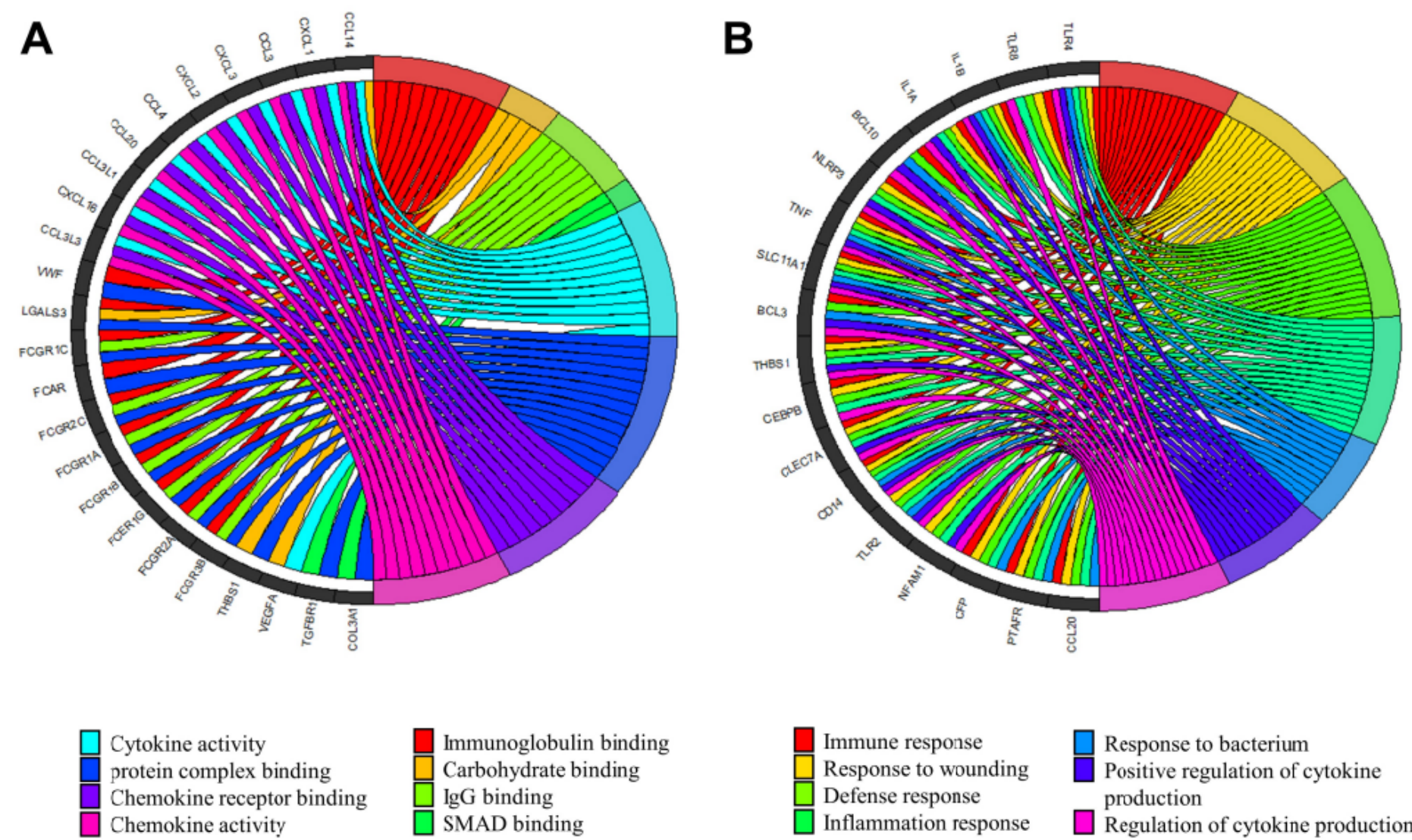

Response to bacterium Positive regulation of cytokine production

$\begin{array}{ll}\text { Chemokine receptor binding } & \text { lgG binding } \\ \text { Chemokine activity } & \square \text { SMAD binding }\end{array}$

Inflammation response

Regulation of cytokine production

\section{Figure 3}

GO enrichment analyses of DEGs. Circle plot of top (a) molecular function and (b) biological process enrichment analysis of DEGs. GO enrichment is ranked by their p-value. GO, Gene Ontology. 

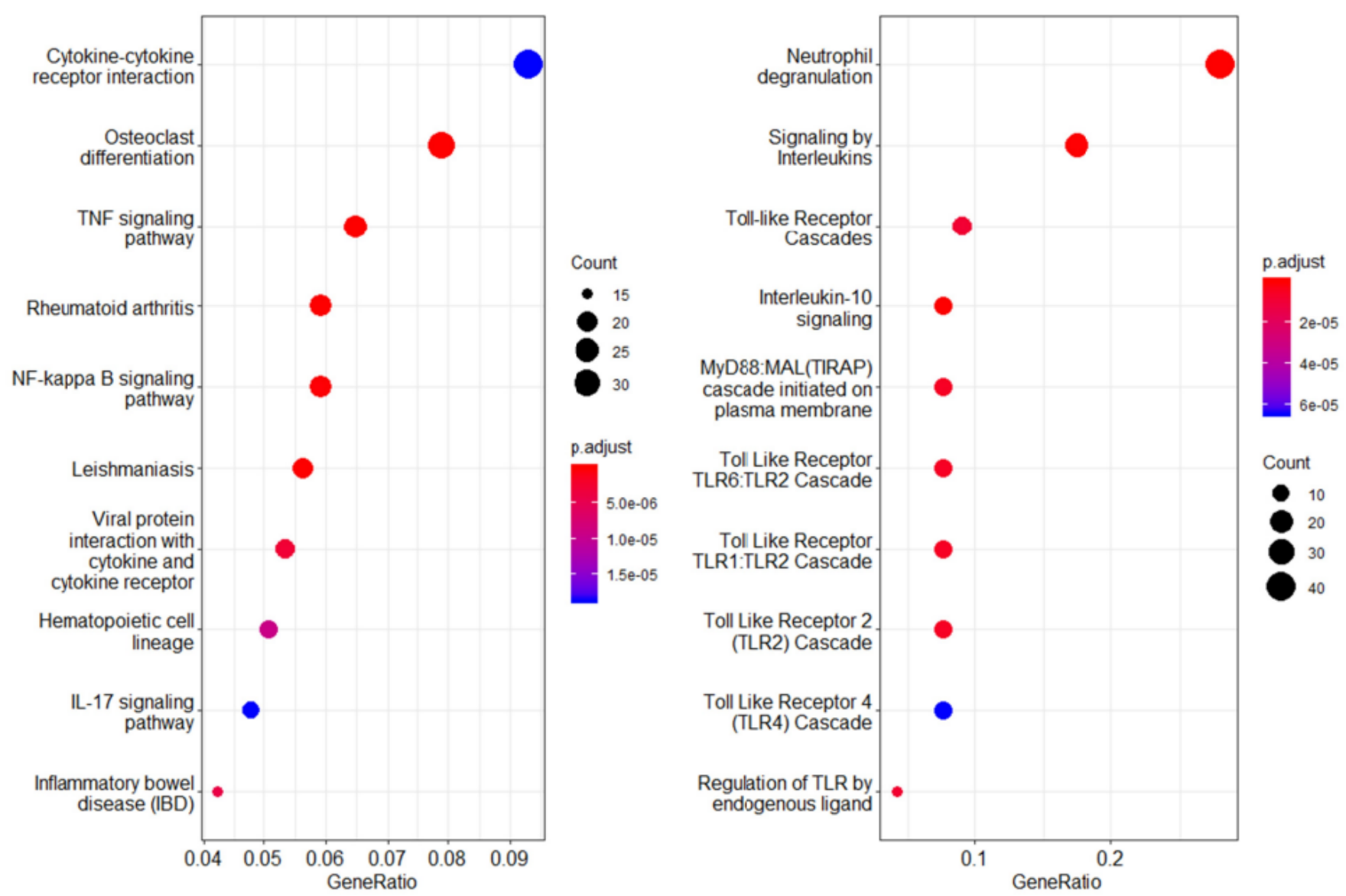

Figure 4

KEGG and Reactome pathways enrichment analyses of DEGs. (a) Bubble plot of KEGG pathway enrichment analysis of DEGs. (b) Bubble plot of Reactome pathway enrichment analysis of DEGs. Pathways enrichement is ranked by their p-value. KEGG, Kyoto Encyclopaedia of Genes and Genomes. 


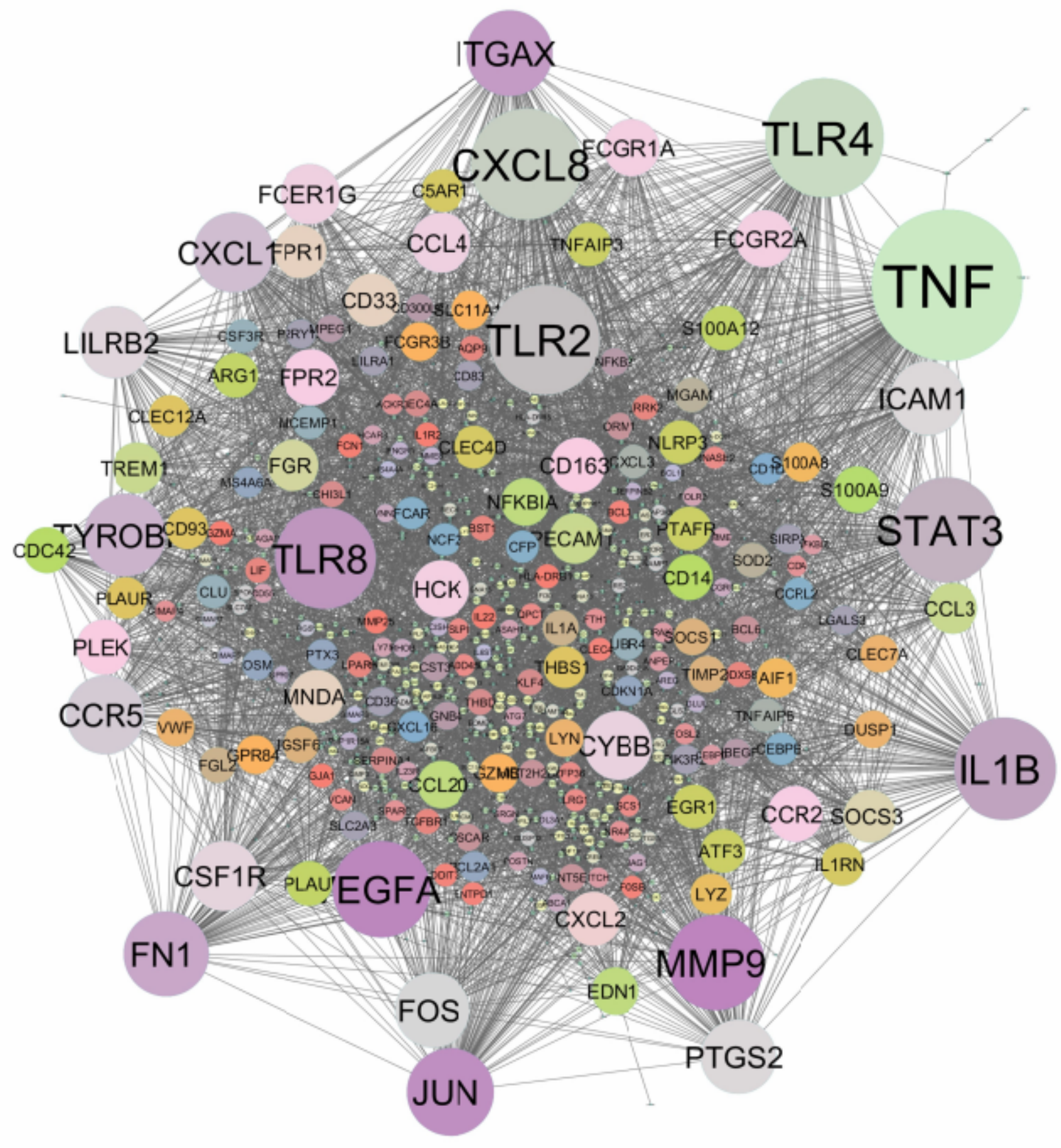

Figure 5

Significant protein interaction map. DEGs protein-protein interaction network (PPI) in circulating endothelial cells with displaying top genes with their general centrality parameters obtained from network analysis. Node sizes is based on the degree of connectivity of the nodes. 
A

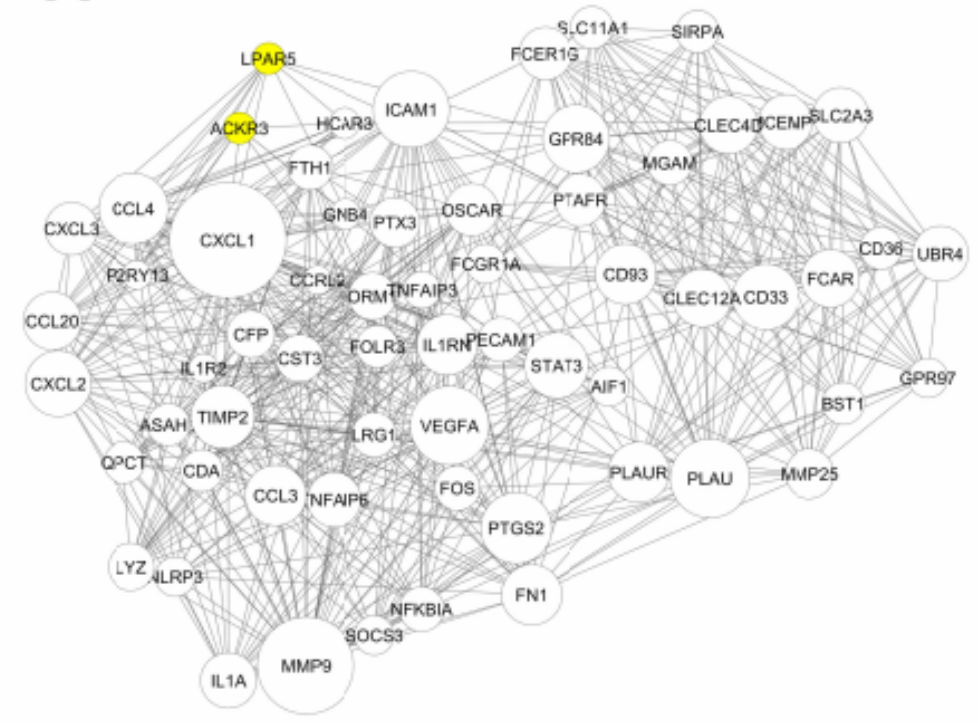

C

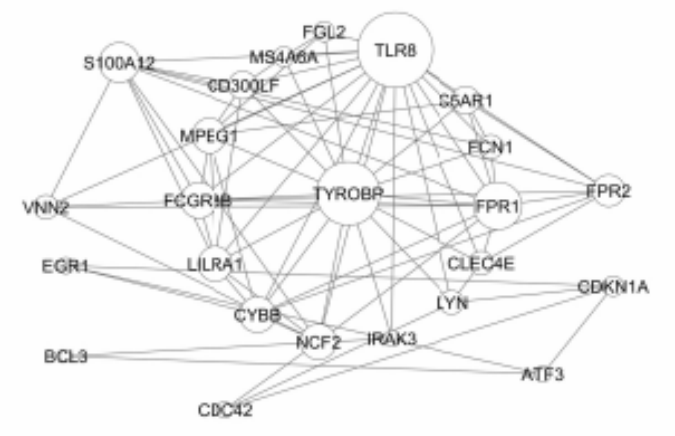

B
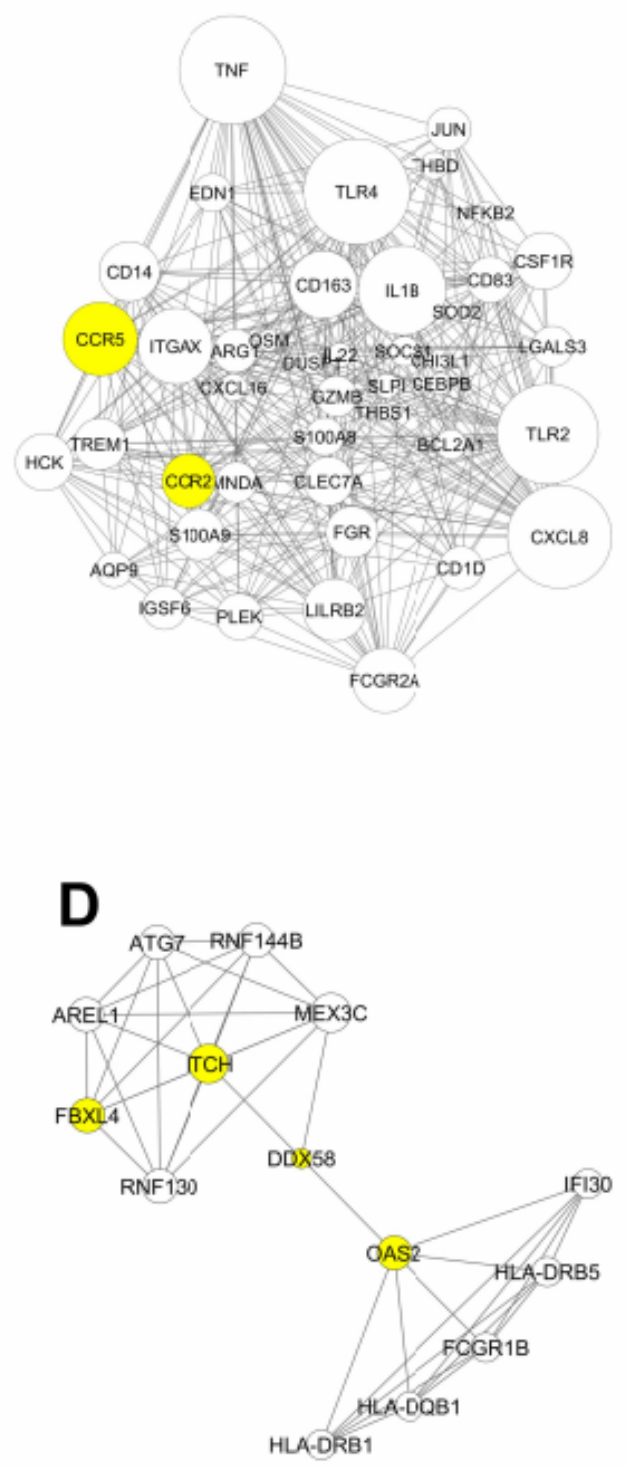

Figure 6

Modules identification. (a-d) MCODE most significant modules in the PPI network of the DEGs. The nodes indicate the DEGs and the edges indicate the interactions between two genes. Yellow for down-regulated genes. 

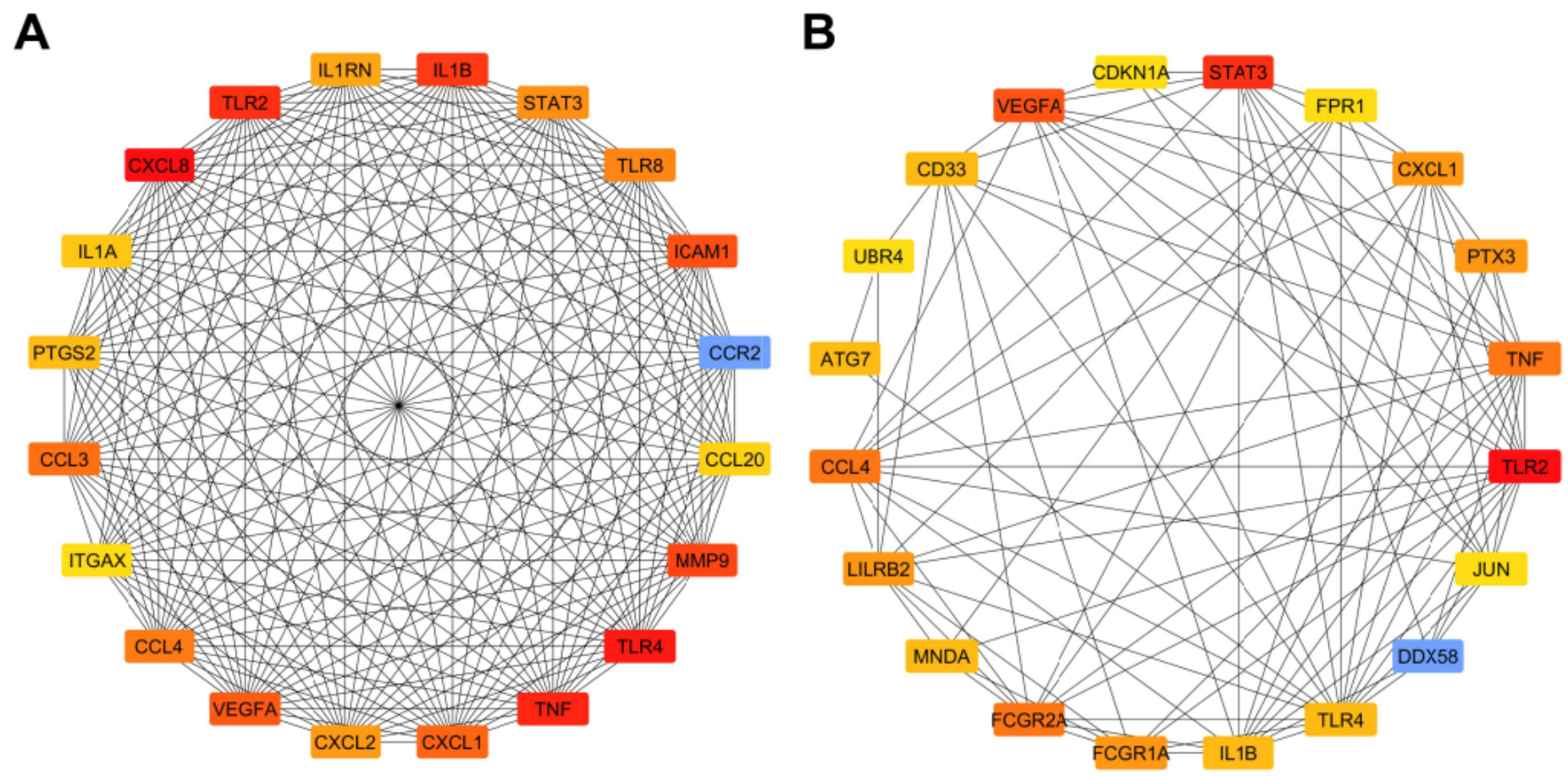

\section{Figure 7}

PPI network of the top 20 (a) hub and (b) bottleneck genes extracted from most significant modules (Color code, : deeper colors indicates higher scores in the MCC analysis Blue for down-regulated gene, others are up-regulated genes). 
A

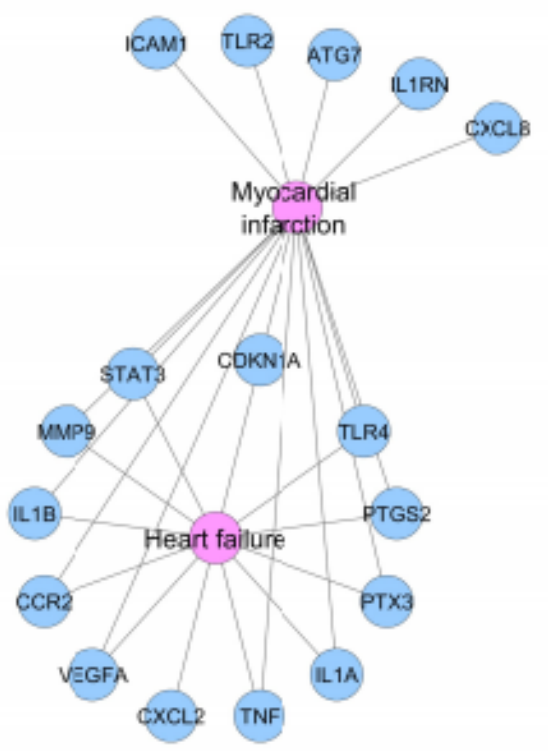

B

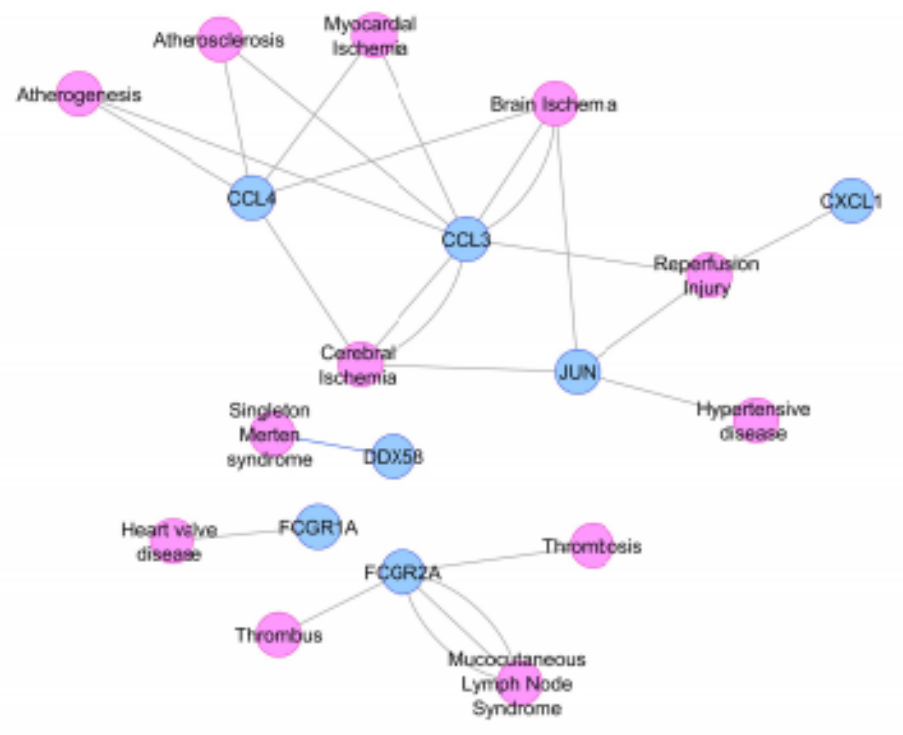

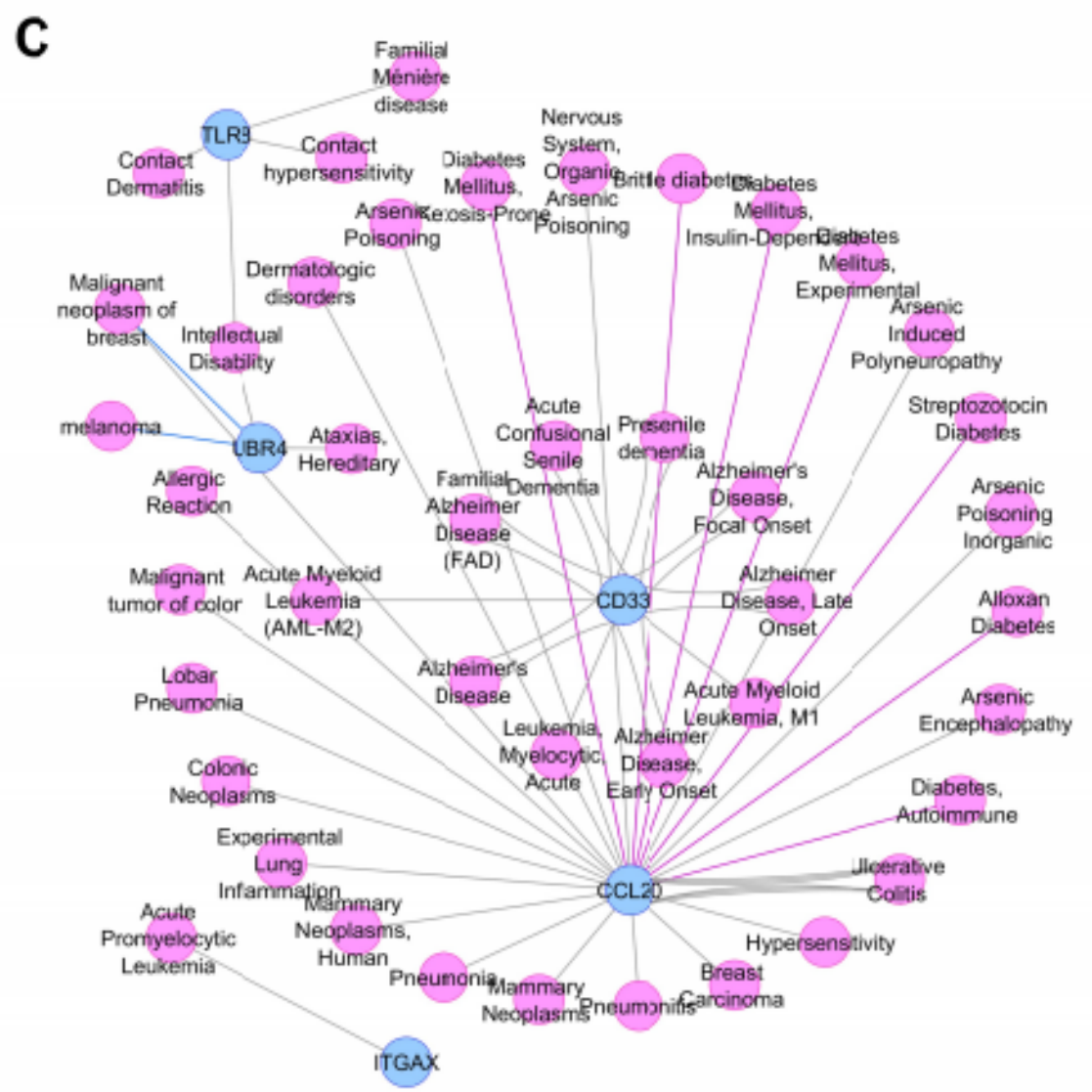

\section{Figure 8}

Network analysis of hubs and bottlenecks related diseases using DisGenNET database (a) Network of Myocardial infarction and Heart failure disease-gene associations from hub and bottleneck genes. (b) Cardiovascular disease association of remaining hub and bottleneck genes. (c) Unassociated cardiovascular genes and their linked disease. 


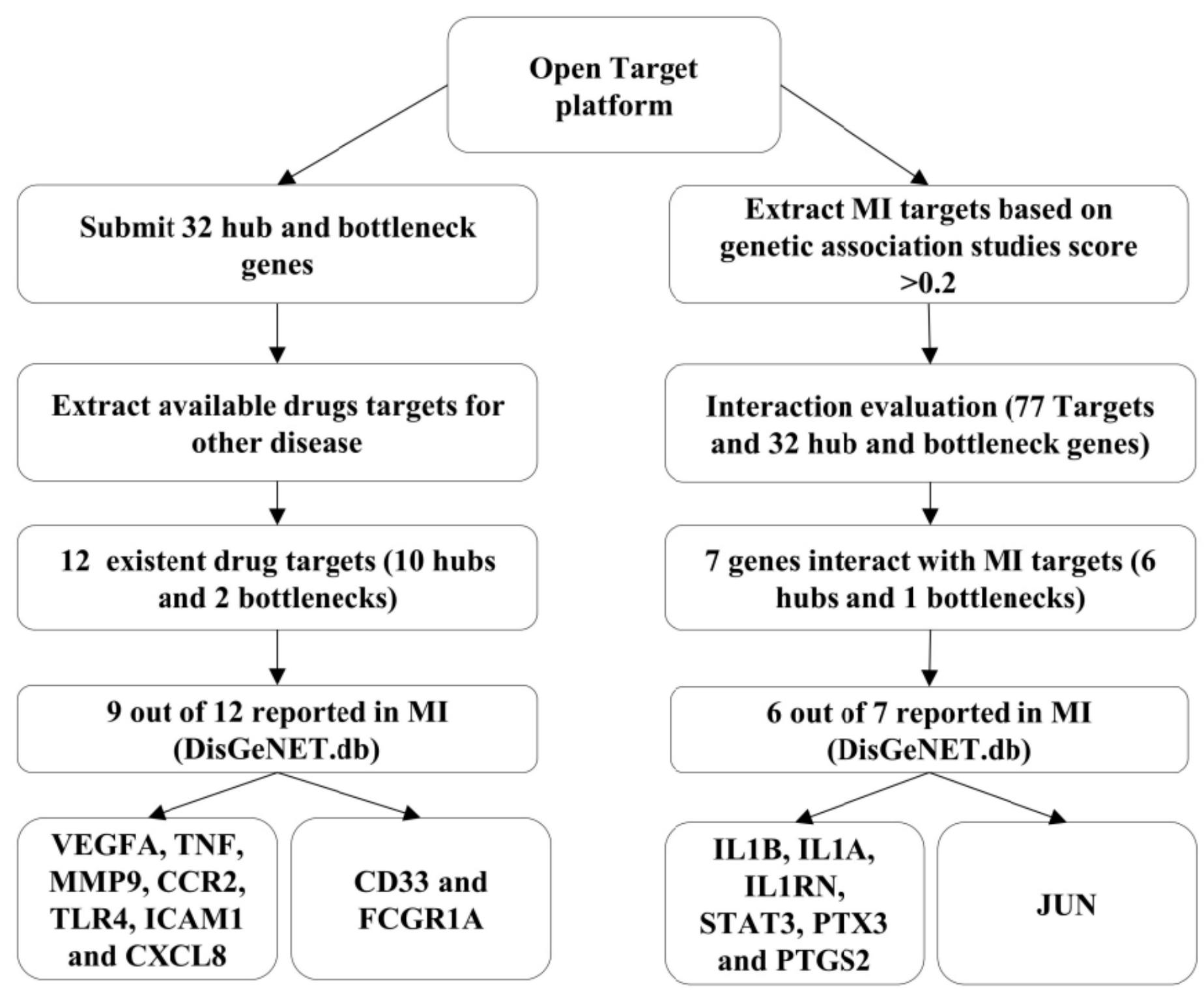

Figure 9

Drug target screening workflow using Open Targets platform.

\section{Supplementary Files}

This is a list of supplementary files associated with this preprint. Click to download.

- Additionalfiles2.xlsx

- Additionalfiles1.pdf 